\title{
Ginkgo biloba preparation prevents and treats senile dementia by inhibiting neuro-inflammatory responses
}

\author{
Xueneng Guan ${ }^{1}$, Jinyou $\mathrm{Xu}^{2}$, Jiangyun Liu ${ }^{2}$, Jie $\mathrm{Wu}^{3}$, Ling Chen ${ }^{1}$ \\ ${ }^{1}$ Department of Physiology, Nanjing Medical University, Jiangsu Nanjing 211166, ${ }^{2}$ Department of Neurology, ${ }^{3}$ Phase Clinical \\ Trial Center, Affiliated Hospital of Integrated Traditional Chinese and Western Medicine, Nanjing University of Chinese \\ Medicine, Jiangsu Nanjing 210038, China
}

*For correspondence: Email: jh1164@163.com

Sent for review: 25 July 2018

Revised accepted: 28 September 2018

\begin{abstract}
Purpose: To study the effect of Ginkgo biloba preparation on senile dementia and the mechanism of its action.

Methods: Sprague Dawley (SD) rat model of chronic cerebral hypoperfusion was produced by vascular occlusion (2-VO). The rats were administered Ginkgo biloba preparation via intra-gastric route $4 \mathrm{~h}$ after the operation, and then at 7:30 am every day at a dose of $100 \mathrm{mg} / \mathrm{kg}$ per day $(0.5 \mathrm{~mL} / 100 \mathrm{~g}$, per day) for 28 days. One group of untreated model rats, and a reference group served as controls. Garcia composite score was used to evaluate the recovery of neurological function in the rats after operation. Morris water maze test was conducted to assess learning and memory abilities. Western blot was used to measure protein expressions of BACE1, TRP1 and RAGE. Serum levels of inflammatory factors IL1, IL6 and TNF were assayed by ELISA.

Results: Garcia composite score showed that the neurological function of the SD rats was significantly impaired by the blockage of blood flow to the bilateral common carotid artery. However, neurological function was gradually recovered by treatment with Ginkgo biloba preparation. The escape latency and swimming distance of the rats were significantly shortened, and the number of platform crossings was gradually increased by the Ginkgo biloba preparation. With time, there was no significant difference in swimming speed between the groups. Western blot data showed that expression of BACE1, TRP1 and RAGE gradually decreased. Results from ELISA indicate that with time, Ginkgo biloba preparation decreased the expressions of IL-1, IL-6, and TNF in the reference group.

Conclusion: The preventive and therapeutic effects of Ginkgo biloba preparation extract on senile dementia may be related to its inhibition of neuro-inflammatory reaction.
\end{abstract}

Keywords: Alzheimer disease, Neuro-inflammatory reactions, Ginkgo biloba preparation

\footnotetext{
This is an Open Access article that uses a funding model which does not charge readers or their institutions for access and distributed under the terms of the Creative Commons Attribution License (http://creativecommons.org/licenses/by/4.0) and the Budapest Open Access Initiative (http://www.budapestopenaccessinitiative.org/read), which permit unrestricted use, distribution, and reproduction in any medium, provided the original work is properly credited.
}

Tropical Journal of Pharmaceutical Research is indexed by Science Citation Index (SciSearch), Scopus, International Pharmaceutical Abstract, Chemical Abstracts, Embase, Index Copernicus, EBSCO, African Index Medicus, JournalSeek, Journal Citation Reports/Science Edition, Directory of Open Access Journals (DOAJ), African Journal Online, Bioline International, Open-J-Gate and Pharmacy Abstracts

\section{INTRODUCTION}

Senile dementia has become a global public health concern, especially with the advent of aging societies. Alzheimer's disease (AD), the most common type of senile dementia, is a neurodegenerative disease characterized by comprehensive decline in cognitive function, disorders in mental behavior, and ultimately loss of capacity for performing functions associated 
with daily living. The disease is of sudden onset, but becomes progressively aggravated [1]. It has poor prognosis, and due to poor understanding of its pathogenesis, it has no cure yet. Thus, effective management of the disease requires the elucidation of its pathogenesis as well as timely intervention. Traditional Chinese Medicine (TCM) plays an increasing important role in the treatment of $A D$, due to its multiple targets. Studies have indicated that TCM has a promising prospect in AD treatment.

Ginkgo biloba preparation is used for the prevention and treatment of cerebrovascular diseases. It is also used for the improvement of cognitive function in senile dementia patients. The aim of the present study was to investigate the mechanism through which Ginkgo biloba inhibits neuro-inflammatory responses. In addition, the mechanism involved in the prevention and treatment of senile dementia by Ginkgo biloba was studied.

\section{EXPERIMENTAL}

\section{Instruments, drugs and reagents}

Millipore supplied the PVDF membrane used in this study, while ECL luminescent liquid was purchased from Thermo Fisher. Enhanced BCA protein concentration assay kit was product of Biyuntian.

Morris Water Maze was purchased from Shanghai Jiliang Software Technology, JLBEHNMWMG; SDS-PAGE Electrophoresis equipment and Wet Transfer Tester were products of BioRad, while Tanon Imaging System and Multiskan MK3 Instrument were products of Tanon and Thermo, respectively.

\section{Establishment of chronic cerebral hypoper- fusion model}

Sprague Dawley (SD) rats were anesthetized and the bilateral common carotid arteries were isolated. The distal and proximal ends of the arteries were ligated separately and cut from the middle to ensure blockage of blood flow. The anal temperature of the rats was maintained at 36.5 - $37.5{ }^{\circ} \mathrm{C}$ during the operation. After the operation, the rats were sent to a ventilated and air-conditioned animal house where changes in their behavior were carefully monitored. This research was approved by the Animal Ethical Committee of Nanjing Medical University (approval no. 20176271) and conducted according to the guidelines of "Principles of Laboratory Animal Care" (NIH publication no. 8523, revised 1985) [2].

\section{Animal grouping and treatment}

The rats were randomly divided into normal control group, reference group and Ginkgo biloba treatment group (6 rats per group). The normal control group did not receive any treatment. In the Ginkgo biloba treatment group, the rats were administered Ginkgo biloba preparation via intragastric route $4 \mathrm{~h}$ after the operation, and then at 7:30 am every day at a dose of $100 \mathrm{mg} / \mathrm{kg}$ per day $(0.5 \mathrm{~mL} / 100 \mathrm{~g}$, per day) for 28 days. Assessments were carried out on days 1, 7, 14 and 28.

\section{Animal model evaluation criteria and testing methods}

The Garcia composite score (Table 1) was used to evaluate the extent of recovery of neurological function in the postoperative rats at the various time points.

Table 1: Garcia neurological function score format

\begin{tabular}{|c|c|c|}
\hline Test & Manifestation & Score \\
\hline \multirow[t]{4}{*}{ Autonomous movement } & Normal & 3 \\
\hline & Mildly affected & 2 \\
\hline & Severely affected & 1 \\
\hline & Inactive & 0 \\
\hline \multirow{4}{*}{$\begin{array}{l}\text { Symmetry of limb } \\
\text { movements when the rat } \\
\text { tail is suspended }\end{array}$} & & \\
\hline & Symmetry & 3 \\
\hline & Asymmetry & 2 \\
\hline & Hemiplegia & 1 \\
\hline \multirow{5}{*}{$\begin{array}{l}\text { Front paw extension } \\
\text { when the rat tail is lifted } \\
\text { and placed at the edge } \\
\text { of a table }\end{array}$} & & \\
\hline & Symmetry & 3 \\
\hline & Mild asymmetry & 2 \\
\hline & $\begin{array}{l}\text { Obvious } \\
\text { asymmetry }\end{array}$ & 1 \\
\hline & Hemiplegia & 0 \\
\hline \multirow[t]{3}{*}{$\begin{array}{l}\text { Ability to climb and hold } \\
\text { iron cages }\end{array}$} & $\begin{array}{l}\text { Climbs easily, } \\
\text { Tight grip }\end{array}$ & 3 \\
\hline & $\begin{array}{l}\text { Neurological } \\
\text { damage on one } \\
\text { side }\end{array}$ & 2 \\
\hline & $\begin{array}{l}\text { Can't climb or } \\
\text { circle }\end{array}$ & 1 \\
\hline \multirow[t]{3}{*}{ Body sensation } & $\begin{array}{l}\text { Bilateral } \\
\text { symmetry }\end{array}$ & 3 \\
\hline & $\begin{array}{l}\text { Symmetry on one } \\
\text { side }\end{array}$ & 2 \\
\hline & $\begin{array}{l}\text { No sensation on } \\
\text { one side }\end{array}$ & 1 \\
\hline \multirow{3}{*}{$\begin{array}{l}\text { Reaction to a touch on } \\
\text { the whiskers }\end{array}$} & Symmetry & 3 \\
\hline & Asymmetry & 2 \\
\hline & $\begin{array}{l}\text { No sensation on } \\
\text { one side }\end{array}$ & 1 \\
\hline
\end{tabular}

Trop J Pharm Res, October 2018; 17(10): 1962 
Morris water maze for assessing learning and memory in rats

The Morris water maze consisted of a circular pool of diameter $120 \mathrm{~cm}$ and height $60 \mathrm{~cm}$. It contained a platform of $50 \mathrm{~cm}$ and diameter of 10 $\mathrm{cm}$, which was 0.5 to $1 \mathrm{~cm}$ below the water surface. The water temperature was $22 \pm 1^{\circ} \mathrm{C}$. A camera with a display system was placed above the maze. A computer automatically tracked the timing, and simultaneously recorded the swimming trajectory of the rats. Twenty-four hours to the test, each group of rats was allowed to swim freely from the four quadrants of the pool for $120 \mathrm{~s}$, to adapt to the water temperature and environment. Rats with difficulties in swimming were identified and removed. Each group of rats were tested every morning. The positioning navigation test was first carried out for a total of four days. During the test, a hidden platform was placed in the fourth quadrant, and the rats were placed in the pool from the four quadrants facing the pool wall with a water interval of $40 \mathrm{~s}$.

The time taken for a rat to find and climb the hidden platform in the fourth quadrant was recorded as the escape latency. The observation time was $60 \mathrm{~s}$, and if the rat was unable to locate the platform within $60 \mathrm{~s}$, it was led to the platform and placed there for $40 \mathrm{~s}$, and its escape latency was recorded as $60 \mathrm{~s}$.

\section{Space search experiment}

The platform was removed on the fifth day, but the experimental procedure was the same as before. The point of placement of the rats was randomly selected. The search time of the rat in the quadrant of the original platform within $60 \mathrm{~s}$, the ratio of the distance to the fourth quadrant to the total distance, and the number of times the platform was crossed, were recorded. During the test, all the items around the pool, and the experimenter's location were fixed.

\section{Collection and fixation of specimens}

Blood (2 $\mathrm{mL})$ samples were collected through cardiac puncture from each rat. The blood samples were kept at room temperature for $3 \mathrm{~h}$ and centrifuged at $3000 \mathrm{rpm}$ for $15 \mathrm{~min}$. The serum samples obtained were kept at $-70{ }^{\circ} \mathrm{C}$ for use in ELISA. Three rats in each group were perfused with normal saline at ascending aorta, and then the brains were excised for removal of the olfactory lobe, cerebellum and low brain stem. One side of the cerebral hemisphere was placed in an ice bath and homogenized. The homogenate was centrifuged at $3000 \mathrm{rpm}$ at $4{ }^{\circ} \mathrm{C}$ for $15 \mathrm{~min}$, and the supernatant was taken and stored at $-80{ }^{\circ} \mathrm{C}$ for Western blot assays. The other 3 rats were perfused with normal saline, and thereafter with $4 \%$ paraformaldehyde at 4 ${ }^{\circ} \mathrm{C}$. Their brains were excised and placed in formalin for $48 \mathrm{~h}$ for routine processing into paraffin sections for light microscopy. The normal control group and reference group were treated the same way.

\section{Determination of protein changes by western blot}

The rat brain tissue sample was excised and homogenized to extract total protein, and BCA protein quantification kit was used to quantify the protein. First, electrophoresis (SDS-PAGE) was carried out with separating gel and concentrated gel. Then, the separated proteins were transferred to PVDF membrane, and blocked with $5 \%$ skim milk powder for $1 \mathrm{~h}$ at room temperature, washed 3 times with TBST for 10 min, and incubated at $4{ }^{\circ} \mathrm{C}$ with primary antibody overnight. Thereafter, it was washed thrice with TBST, each wash for $10 \mathrm{~min}$. Then, the diluted secondary antibody was added. After $2 \mathrm{~h}$, it was again washed thrice with TBST, each wash for $10 \mathrm{~min}$. The protein bands were detected by using chemiluminescence kits (Thermo ECL) according to the kit instructions, and photographed using Tanon imager.

Assay of serum inflammatory factors IL1, IL6 and TNF

Blood was collected from the rats and placed in pro-coagulant collection tubes at room temperature for $2 \mathrm{~h}$, and centrifuged at $3000 \mathrm{rpm}$ for 20 min. Serum levels of IL1, IL6 and TNF were determined using ELISA kits and following the manufacturer protocol.

\section{Statistical analysis}

The data were statistically analyzed with software SPSS version 18.0. Each parameter was expressed as mean $\pm \mathrm{SD}$. One-way analysis of variance (ANOVA) was used for data comparison between groups, while LSD t-test was used for intra-group comparisons. Spearman correlation test was used for correlation analysis. Values of $p<0.05$ were assumed statistically significant.

\section{RESULTS}

\section{Neurological function scores}

The Garcia composite scores and the experimental results are shown in Table 2. The neurological function of SD rats was significantly 
impaired by the blockage of bilateral common carotid blood flow. However, the neurological function was gradually recovered as a result of treatment with Ginkgo biloba preparation within the intervention periods (Figure 1).

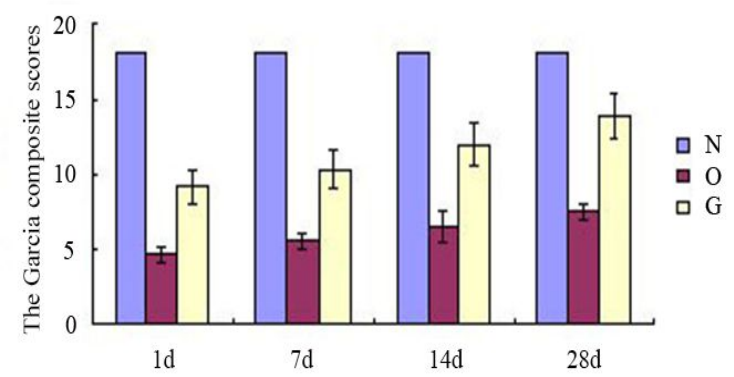

Figure 1: Neurological function scores of the rat groups. Note: N, normal control group; O, reference group; G, Ginkgo biloba preparation group

\section{Rat spatial memory learning function}

Morris water maze trajectory at different time points in the control group and Ginkgo biloba preparation intervention group are shown in Figure 2. The Ginkgo biloba intervention significantly shortened the escape latency in the hypoperfusion model rats (Table 3 ).

The results on Table 4 show that the mean swimming distance for rats in the reference group was significantly longer than the mean swimming distance of rats in the normal control group.

The number of times the platform was crossed also increased with time after administration of Ginkgo biloba (Table 5). a
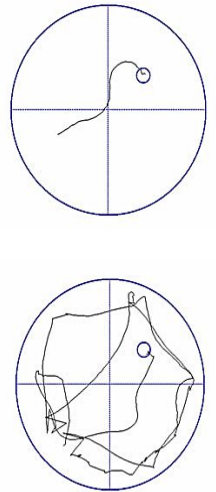

g

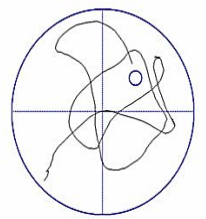

b
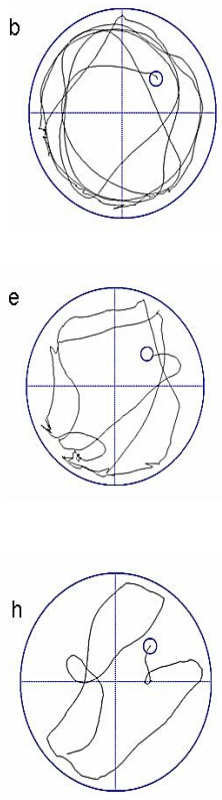
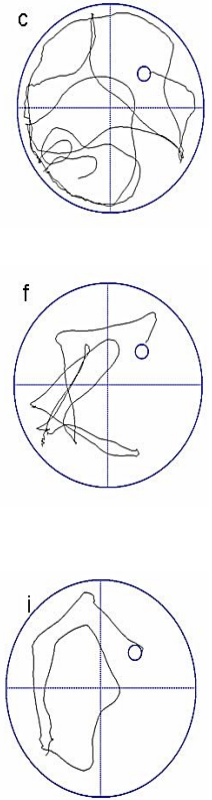

Figure 2: Morris water maze trace diagram. Normal control group (a); reference group $(b-e)$ on days 1,7 , 14 and 28; ginkgo leaf preparation treatment group ( $f-$ i) on days $1,7,14$, and 28

Table 2: Rat neurological function score

\begin{tabular}{lccc}
\hline Time (days) & Normal control group & Reference group & $\begin{array}{c}\text { Ginkgo biloba } \\
\text { preparation group }\end{array}$ \\
\hline 1 & $18.00 \pm 0.00$ & $4.67 \pm 0.52$ & $9.17 \pm 1.17$ \\
7 & $18.00 \pm 0.00$ & $5.50 \pm 0.55$ & $10.33 \pm 1.21$ \\
14 & $18.00 \pm 0.00$ & $6.50 \pm 1.05$ & $12.00 \pm 1.41$ \\
28 & $18.00 \pm 0.00$ & $7.50 \pm 0.55$ & $13.83 \pm 1.47$ \\
\hline
\end{tabular}

Table 3: Escape latency of rats in the three groups (seconds)

\begin{tabular}{lccc}
\hline Time (days) & Normal control group & Reference group & $\begin{array}{c}\text { Ginkgo biloba } \\
\text { preparation group }\end{array}$ \\
\hline 1 & $10.71 \pm 7.93$ & $68.83 \pm 47.64$ & $46.67 \pm 44.18$ \\
7 & $12.42 \pm 6.45$ & $59.50 \pm 49.60$ & $41.83 \pm 40.00$ \\
14 & $9.56 \pm 6.48$ & $51.66 \pm 49.33$ & $40.67 \pm 35.64$ \\
28 & $11.35 \pm 8.64$ & $50.16 \pm 48.27$ & $38.67 \pm 41.46$ \\
\hline
\end{tabular}

Table 4: Total swimming distance of rats in the three groups ( $\mathrm{mm})$

\begin{tabular}{lccc}
\hline $\begin{array}{l}\text { Time } \\
\text { (days) }\end{array}$ & $\begin{array}{c}\text { Normal } \\
\text { control group }\end{array}$ & Reference group & $\begin{array}{c}\text { Ginkgo biloba preparation } \\
\text { group }\end{array}$ \\
\hline 1 & $2688.62 \pm 1885.57$ & $16739.33 \pm 997.53$ & $9755.72 \pm 9454.25$ \\
7 & $2103.53 \pm 1635.46$ & $14313.01 \pm 12779.73$ & $8797.72 \pm 6626.61$ \\
14 & $3012.24 \pm 1834.56$ & $11209.93 \pm 10506.19$ & $7829.72 \pm 7209.91$ \\
28 & $2564.86 \pm 1563.48$ & $10045.55 \pm 8820.69$ & $6843.86 \pm 5164.85$ \\
\hline
\end{tabular}


Table 5: Number of times the rats crossed the platform

\begin{tabular}{lccc}
\hline $\begin{array}{l}\text { Time } \\
\text { (days) }\end{array}$ & $\begin{array}{c}\text { Normal } \\
\text { control } \\
\text { group }\end{array}$ & $\begin{array}{c}\text { Reference } \\
\text { group }\end{array}$ & $\begin{array}{c}\text { Ginkgo biloba } \\
\text { preparation } \\
\text { group }\end{array}$ \\
\hline 1 & $4.14 \pm 1.07$ & $0.83 \pm 0.75$ & $1.89 \pm 1.02$ \\
7 & $3.94 \pm 1.12$ & $0.92 \pm 0.69$ & $2.14 \pm 1.12$ \\
14 & $4.08 \pm 1.06$ & $0.82 \pm 0.71$ & $2.56 \pm 1.14$ \\
28 & $4.35 \pm 1.14$ & $0.98 \pm 0.81$ & $3.01 \pm 1.23$ \\
\hline
\end{tabular}

The swimming speeds of rats in the three groups were comparable, as shown in Table 6. There were no significant differences between the groups.

\section{Expressions of BACE1, TRP1 and RAGE in rat brain tissue}

The effect of Ginkgo biloba on the expressions of BACE1, TRP1 and RAGE proteins in the brain tissues of the hypoperfusion rats are shown in Figure 3. Gray value analysis of BACE1 (Figure 4), TRP1 (Figure 5), and RAGE (Figure 6) indicate that these proteins were significantly higher in the chronic cerebral hypoperfusion model rats than in the control group. However, intervention with Ginkgo biloba preparation led to a gradual reduction in their levels with time.

\section{Serum levels of IL-1, IL-6, and TNF}

Serum IL-1, IL-6, and TNF at different time points in the control group and Ginkgo biloba preparation intervention group are shown in Figures 7. These indicators were significantly higher than their corresponding values in the control group, but became gradually decreased with time after intervention with Ginkgo biloba preparation.

\section{DISCUSSION}

Alzheimer's disease poses serious harm to human health. Increasing evidence suggest that immuno-inflammatory mechanisms may play important roles in the pathogenesis of $A D$. Researchers have identified the inflammatory processes associated with senile plaques (SP) and neurofibrillary tangles (NFT) as the main features of $A D$ [3].

Table 6: Swimming speed of rats in the three groups

\begin{tabular}{lccc}
\hline $\begin{array}{l}\text { Time } \\
\text { (days }\end{array}$ & $\begin{array}{c}\text { Normal } \\
\text { control } \\
\text { group }\end{array}$ & Reference group & $\begin{array}{c}\text { Ginkgo } \\
\text { biloba } \\
\text { preparati } \\
\text { on group }\end{array}$ \\
\hline 1 & 239.01 & $209.19 \pm 32.49$ & $\begin{array}{c}206.18 \pm 4 \\
9.95\end{array}$ \\
7 & \pm 50.74 & $220.3 \pm 29.64$ & $240.58 \pm 4$
\end{tabular}

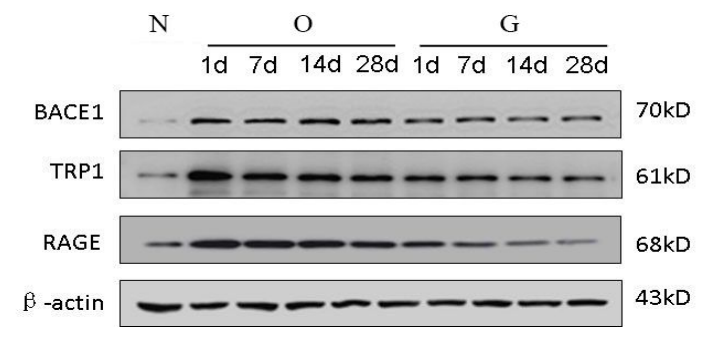

Figure 3: BACE1, TRP1, RAGE protein expressions. Note: $N$, normal control group; $O$, reference group; $G$, Ginkgo biloba preparation group

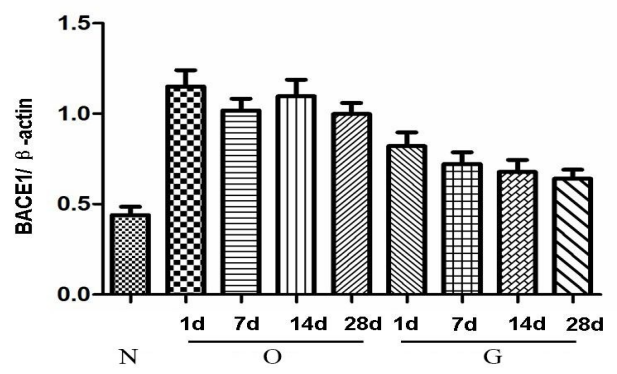

Figure 4: Gray ratio of BACE1 to $\beta$-actin. Note: $N$, normal control group; O, reference group; G, Ginkgo biloba preparation group

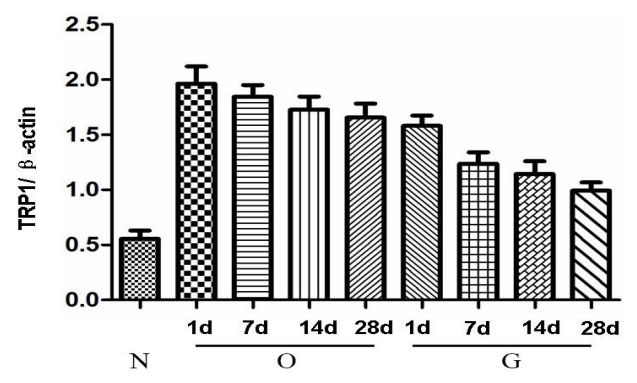

Figure 5: Gray ratio of TRP1 to $\beta$-actin. Note: $N$, normal control group; O, reference group; G, Ginkgo biloba preparation group

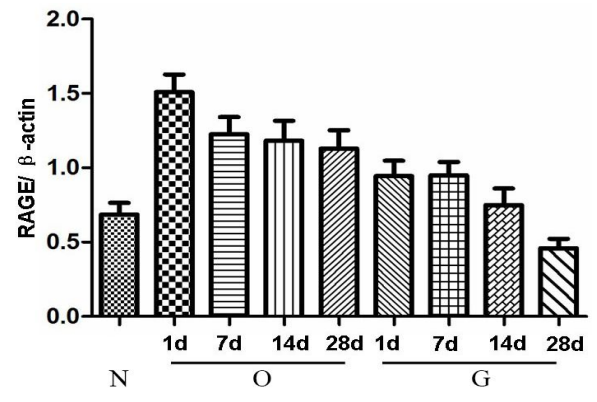

Figure 6: Gray scale ratio of RAGE to $\beta$-actin. Note: $N$, normal control group; O, reference group; $G$, Ginkgo biloba preparation group

\begin{tabular}{cccc} 
& \pm 45.25 & & 4.28 \\
14 & 216.45 & $230.73 \pm 55.80$ & $235.13 \pm 4$ \\
& \pm 56.48 & & 1.18 \\
28 & 199.89 & $222.37 \pm 39.95$ & $216.02 \pm 3$ \\
& \pm 38.45 & & 5.32 \\
\hline & & & \\
& & & \\
& &
\end{tabular}

Trop J Pharm Res, October 2018; 17(10): 1965 

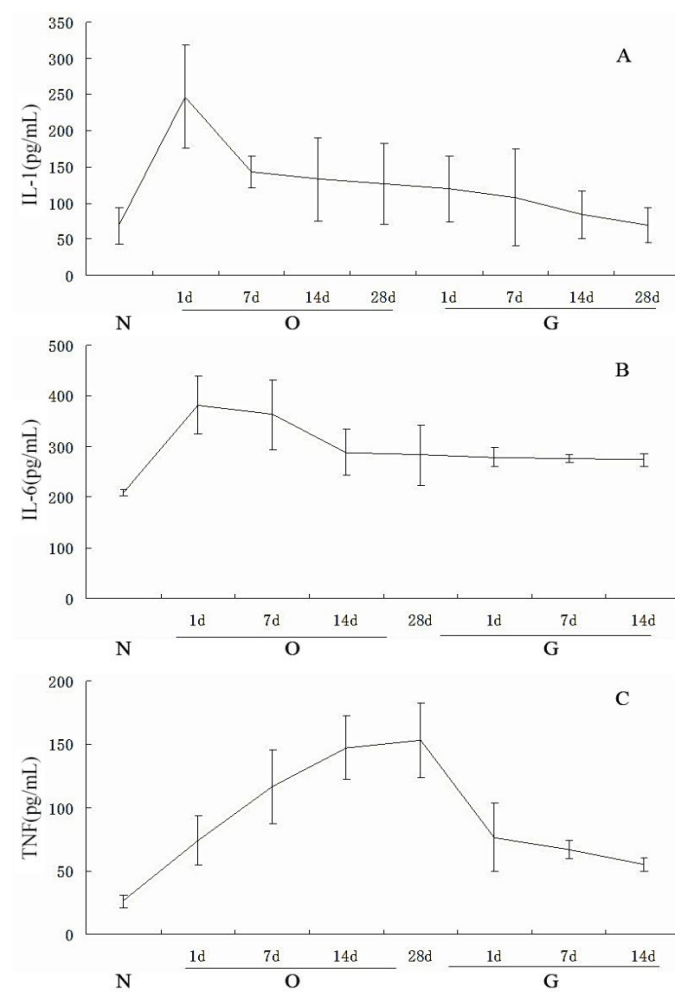

Figure 7: Serum levels of IL-1, IL-6, and TNF. Note: $A$, Serum IL-1 levels; $B$, serum IL-6 levels; $C$, serum TNF levels; $N$, normal control group; $O$, reference group; G, Ginkgo biloba preparation group

Studies have suggested that microglia inflammatory response to $A \beta$ deposition is the core mechanism involved in the pathogenesis of $A D$, which is closely related to the neuronal degeneration $[4,5]$.

In this study, the AD model of chronic cerebral hypoperfusion was established by blocking bilateral common carotid artery blood flow so as to verify the effects of BACE1, RAGE, TRP1 and inflammatory factors IL-1, IL-6, and TNF. The results showed that in the chronic cerebral hypoperfusion reference group, these indicators were significantly increased, indicating that inflammatory response and mediators played an important role in the development of $A D$. Previous studies have shown that reductions in ischemia or cerebral blood flow may constitute early events that cause increases in BACE1 expression and activity, which in turn lead to increased $A \beta$ levels [6-8].

The production of IL-1 by microglia is the starting point in the stimulation of $A \beta$. In addition to upregulating the expression of other cytokines by microglia or astrocytes, IL-1 induces the formation of complements, acute phase proteins, oxygen free radicals, NO, and $\beta$-APP. These act on glial cells or neurons, promoting the production of other inflammatory molecules and continuous increase in inflammatory products, with impact on nerve growth, neural plasticity, neuronal damage and degeneration [9].

It is known that TNF- $\alpha$ is the main substance that activates the cytokine cascade in the inflammatory responses. It acts directly on astrocytes and oligodendrocytes, causing damage to myelin and oligodendrocytes and even apoptosis, which in turn has a greater cytotoxic effect than TNF- $\alpha$ [10]. The TLRmediated signaling leads to the activation of innate immune cells, and the expression and secretion of a variety of pro-inflammatory cytokines such as tumor necrosis factor (TNF- $\alpha$ ), interleukin IL-12 and IL-6. Studies have suggested that overexpression and release of IL$1 \beta$ initiates inflammatory injury [11]. Moreover, IL- 6 and TNF- $\alpha$, in synergy with IL- $1 \beta$, induce the production of other cytokines, and interact with $A \beta$ to form a vicious circle which promotes the onset of $A D[12,13]$.

The pathogenesis of $A D$ can also be accelerated by IL-6, a cytokine with various biological functions. It has been reported high levels of IL-6 in the brain are implicated in the pathogenesis of neuronal degeneration in transgenic mice, and may affect learning and memory in the pathway involved in the formation of memory blots [14]. Therefore, the results showing induction of neuronal injury by the cascade of inflammatory cytokines are consistent with the results obtained in the chronic cerebral hypoperfusion reference group. Thus, vascular factors may be some of the inflammation mechanisms involved in the development of $A D$.

Ginkgo biloba has received the attention of the worldwide medical community for the special effects of its active ingredients on the prevention and treatment of diseases such as cardiovascular and cerebrovascular diseases. It contains unique flavonoids, terpenes and ginkgolic acids that cause allergic reactions. It causes the dilation of coronary vessels and cerebrovascular vessels, thereby improving microcirculation, promoting metabolism of heart and brain tissue, and protecting nerve cells. It can also specifically antagonize PAF, reduce platelet aggregation, improve blood rheology, scavenge free radicals, and inhibit cell membrane lipid peroxidation and oxidative modification of low-density lipoproteins.

Long-term clinical studies have also found that ginkgo leaf preparations can improve cognitive function in patients with vascular dementia [15]. Based on the latter, the present study was conducted to investigate the effects of Ginkgo 
biloba preparation on the recovery of neurological deficits, BACE1, RAGE, TRP1, IL-1, IL-6, and TNF in a rat model of chronic cerebral hypoperfusion. This was with a view to determining the mechanism involved in the beneficial effects of Ginkgo biloba preparations in the treatment of AD.

The results showed that Ginkgo biloba preparation improved spatial and dementia memory of rats. There were gradual decreases in BACE1, RAGE, TRP1, IL-1, IL-6 and TNF after administration of Ginkgo biloba preparation in dementia rats, leading to recovery of neurological function. Based on these results, it can be speculated that Ginkgo biloba improves microcirculation by expanding cerebral vasculature. This effectively inhibits the expression of inflammatory factors, and reduces inflammatory damage to neurons, thereby improving the spatial exploration memory ability of dementia rats. This is beneficial in the treatment of $A D$.

\section{CONCLUSION}

Vascular factors participate in the pathogenesis of $A D$ through inflammatory mechanisms. There is currently no definite and effective treatment for $A D$, but more and more studies favor the inhibition of the AD-associated inflammatory responses with drugs so as to protect the neurons. The results obtained in this study indicate that Ginkgo biloba preparation improves microcirculation, inhibits the expression of inflammatory factors, and reduces inflammatory damage to neurons, thereby improving the spatial exploration memory of dementia rats. Thus, it has a good potential for development for the management of $A D$.

\section{DECLARATIONS}

\section{Conflict of Interest}

No conflict of interest associated with this work.

\section{Contribution of Authors}

This work was done by the authors named in this article and the authors accept all liability resulting from claims which relate to this article and its contents. The study was conceived and designed by Ling Chen; Jinyou Xu, Jiangyun Liu, Jie Wu collected and analysed the data; Xueneng Guan wrote the text and all authors have read and approved the text prior to publication.

\section{REFERENCES}

1. Aguzzi A. Neurodegeneration: Alzheimer's disease under strain. Nature 2014; 512(7512): 32-34.

2. World Health Organization. Principles of laboratory animal care. WHO Chron 1985; 39: 51-56.

3. Liu JG, Yao MJ, Huang ZB, Zhao WM, Li H, Liu LT. Effect of Huannaoyicong Prescription on inflammatory factors in brain tissue and $N F-K B$ expression in hippocampus of cognitive impairment rat. Chin $J$ Tradit Chin Med Pharm 2011; 26(1): 158-162.

4. Ho I, Qin WP, Stetka BS, Pasinetti GM. Is there a future for cyclooxygenase inhibitors in Alzheimer's disease? CNS Drugs 2006; 20(2): 85-98.

5. Block ML, Hong JS. Chronic microglia activation and progressive dopaminergic neurotoxicity. Biochem Soc Trans 2007; 35(5): 1127-1132.

6. Guan XN, Yan FL. Influence of Ginkgo Biloba extract on beta-secretase in rat hippocampal neuronal cultures following chronic hypoxic and hypoglycemic conditions. Neural Regeneration Research 2008; 3(10): 1065-1069.

7. Zhang J, Guan XN, Yan FL. Effect of Egb761 on Activity of $\beta$-secretase in Hippocampus of Old Rats after Chronic Cerebral Hypoperfusion. Chin J Clin Neur sci 2006; 14(5): 454-457.

8. Grammas $P$, Ovasea $R$. Inflammatory factors are elevated in brain microvessels in Alzheimer's disease. Neurobiology Aging 2001; 22 (6): 837-842.

9. Wei DX, Chen JP. Microglia and Alzheimer's disease. Foreign Med Sci (Geriatrics) 2000; 11: 248.

10. Velzaquez $P$, David HC, Thomas LP, Andres JT. Aspartate residue in amyloid beta-protein is critical for classical complement pathway activity implication for $A$ Izheimer's disease pathogenesis. Natl Med 1997; 3(1): 77.

11. Shaftel SS, Kyrkanides S, Olschowka J, Miller JN, Johnson RE, O'Banion MK. Sustained hippocampal IL-1 beta overexpression mediates chronic neuroinflammation and ameliorates Alzheimer plaque pathology. Clin Invest 2007; 117(6): 1595-1604.

12. Li L, Zheng JX. Experimental study on effect of Buyang Huanwu decoction on IL-6, TNF- $\alpha, A \beta 1-40$ and $\beta-A P P$ in hippocampus of $A D$ rats. Chin $J$ Tradit Chin Med Pharm 2008; 23(11): 96-97.

13. Angelopoulos $P$, Aqouridaki $H$, Vaiopoulos $H$, Siskou $E$, Doutsou K, Costa V, Baloyiannis SI. Cytokines in Alzheimer's disease and vascular dementia. Int $\mathrm{J}$ Neurosci 2008; 118(12): 1659-1672.

14. Campbell IL, Abraham CR, Masliah E, Kemper P, Inglis $J D$, Oldstone MB, Mucke L. Neurologic disease induced in transgenic mice by cerebral overexpression of interleukin 6. Proc Nat I Acad Sci USA 1993; 90: 1006110065.

15. Ji $X L$, Guan $X N$, Liu WY. Ginkgo biloba preparation improves cognitive function in patients with vascular dementia. Chin J Pract Nerv Dis 2008; 11(11): 114-115. 